\title{
HEDGING STRATEGIES IN THE ADOPTION AND USE OF E-GOVERNMENT SERVICES
}

\author{
Sharif Khan, Salah Kabanda and Adedapo Mobee \\ University Cape Town, \\ Department of Information Systems, South Africa
}

\begin{abstract}
Despite the anticipated benefits of efficiency, cost savings, inclusion and overall citizens' satisfaction; adoption and use of ICT and related technologies in government (e-Gov) remains low in developing countries. One of the main challenges has been trust. It is believed that the online environment poses a series of risk and uncertainties which user's find difficult to navigate through and develop trust. In such uncertain situations, users engage in hedging strategies to shield from the risks that they would be exposed to and ensure themselves from any loss. This study seeks to explore what hedging strategies online users employ to guard against risks associated with the use of e-Gov services. Following an interpretive paradigm and semi-structured interviews as a means of data collection, the study identifies three hedging strategies associated with the adoption of e-Gov services in the Western Cape of South Africa.
\end{abstract}

\section{KEYWORDS}

E-Government, Trust, Hedging

\section{INTRODUCTION}

Governments globally realize that e-Government (eGov) has the potential to improve service delivery and is now considered the instrument through which citizens use to measure government performance (Mutula and Mostert 2010). To date, many governments are advocating for eGov as a means to, among other benefits, reduce cost, enhance citizen trust of government and improve efficiency (Picazo-Vela et al 2012). Despite these benefits and opportunities, the successful implementation is dependent on citizen's willingness to adopt these services (Shareef et al 2011). Rashid and Othman (2010) state that 'although it is clear that the citizen is the main user of eGov services, there are only few studies conducted on the issue specific to citizen adoption of the online service'; and even if studies are done, adoption remains low, implying that we have not adequately understood what factors influence adoption (Lallmahomed et al 2017). Further, the majority of the studies report from a developed economy context, where their contextual challenges and opportunities differ significantly to those present in developing countries. For example, developed economies cite the characteristics of the services themselves as being highly influential for the decision to not use eGov; and that 'technological shortcomings like data security or a lack of usability only play a subordinate role' (Distel 2018). These findings are in contrast for most developing countries were technology related factors are still seen as being significant to citizen's adoption of eGov. The plethora of studies have shown that the most influencing factors include issues of privacy and security risks posed online (Munyoka and Maharaj 2019); performance and time risks associated with e-services as well as quality of services such as system, service and information quality (Alzahrani et al 2018). Prior studies have also identified trust in online IT systems as one of the main predictor of adoption and continued use of online systems (van Esterik-Plasmeijer and van Raaij, 2017).

Alzahrani et al (2018) reiterates that a lack of trust in eGov is the main inhibitor of adoption, mainly due to the inherent risks of online interactions and transactions, and its dependence on the context (Chen et al 2015). The online context presents two conditions which makes trust impotent: uncertainty and vulnerability risk (Mellouli et al 2016). In the face of these conditions, people tend to develop hedging mechanism as a means of self-protection (Reich and Wheeler, 2016). According to D'cruz (2015), hedging is "a defensive posture in the face of uncertainty, a method of mitigating the severity of feared negative outcomes by expending resources to protect oneself in the event" (472). Understanding hedging as a coping strategy when trust is not completely 
conferred in an eGov service is important, as the findings would help developers have better insights into users' needs to improve the design and implementation of online services (Bhattacharya et al, 2012) and consequently increase adoption and usage of eGov services. This study seeks to explore what hedging strategies online users employ to guard against risks associated with the use of e-Gov services.

This study examines this phenomenon in the South African context. Although countries in Africa are seen to lag behind the world in eGov adoption, South Africa is amongst the six African countries, which show a high E-Government Development Index (EGDIs) and possess a high E-Participation Index. As a country that is featured in the top fiftieth percentile along with countries that have EGDIs above the world average of 0.549 (E-government Survey, 2019); South Africa is seen as a good case study for this study.

\section{RELATED WORK}

\subsection{E-Government}

E-Government is traditionally seen as the use of the Internet by government agencies to provide (i) informational services such as policy information to downloadable forms for automobile license renewal; and (2) transactional services to citizens such as filing taxes and conducting online transactions (Venkatesh et al 2016). In this way, the government 'improves transparency, accountability and governance of the public sector services and in so doing it can improve government performance and create new public value for citizens and businesses' (Al-Hujran et al 2015). Currently, the literature is rich on studies on citizen adoption of eGov services. Yet adoption and usage of eGov services remains low, specifically in developing countries who are also now embarking on the use of ICTs to deliver their services. For example, Mauritius is one of the first country in Sub Saharan Africa to obtain a high score on the UN E-Government Development Index for 2014 (Lallmahomed et al, 2017) and is the second top most E-Government ready country in Africa behind Tunisia (UN E - Goverment Survey, 2016). In South Africa, several eGov services are noted such as the electronic filing system, which delivers a means to submit tax returns using internet; as well as the National Traffic Information System (Mutula and Mostert, 2010). Several authors have attributed the lack of adoption to citizen's mistrusts of eGov (Bélanger and Carter 2008).

Chen et al (2015) divides trust in two categories: trust in the entity providing the service, (the government), and trust in the tools used to deliver the service, (the technology). Whilst the former "arises if citizens have confidence in the government, reinforcing perceptions of integrity and reliability; the latter arises when online users trust the tools to be used to deliver the service - especially considering ongoing security and privacy concerns that hinders e-government use" (253). Studies in tools used to deliver the service, have shown that if citizens perceive that using eGov will be easy to use, it will influence the decision to adopt (Shareef et al 2011). For instance, Lallmahomed et al (2017) notes that factors such as performance expectancy, facilitating conditions and perceived value showed significant positive relationship with behavioural intention to use eGov services. These two categories of trust are perceived to be significant factors in influencing trust in the usage of e-Gov services due to potential risk and uncertainties posed online (Chen et al 2015). Alzahrani et al (2016) identify citizen's disposition to trust, demographic factors such as age and internet experience as important aspects influencing trust in eGov. Previous studies have also identified eGov awareness as an important factor for citizen's intention to use eGov services. This is because awareness can translate into recognition of the perceived benefits and may influence adoption (Joseph and Du Plessis, 2015). In addition to awareness of the services offered, Liu and Carter (2018) posits that an individual's awareness of and familiarity with organizational information privacy practices and an eGov system are important as these can potentially influence adoption.

\subsection{Hedging}

Several studies have shown that trust is an essential element of a relationship when uncertainty, or risk, is present (Bélanger and Carter 2008). It is therefore imperative to understand how online users manage during uncertainty. One strategy identified to be used by those in uncertainty situation is hedging - a "strategy of insuring oneself against a loss" (D'cruz, 2015). Hedging is perceived to be one of the most important risk management decisions (Dorfman and Karali 2010) and as such has drawn the attention of policy makers and 
scholars alike (Koga 2017). Jackson (2014) posits that the concept of mistrust gives one of the dominant explanations for hedging. When individuals fail to trust the trustee, they involve themselves in hedging strategies to shield from the risk that the trustee presents. There are several hedging strategies in literature, however, these tend to be concentrated within the financial sector context to examine risk management (Taušer and Čajka, 2016); and others who examine hedging at international political macro level to influence policymaking (Salman, 2017). The former has also been widely used in the context of farming, to manage risks associated with farming by presenting farmers with information on "how to hedge, how much to hedge, when to hedge, etc., by a wide variety of "experts" (Dorfman and Karali, 2010).

Rao et al $(2011,555)$ notes that although hedging is a powerful tool, "it has not been studied in computing systems to handle the uncertainties" such as those that exist in the operation. Attempts to use the hedging concept in information systems is by Hariguna and Berlilana (2017) who shows that: "if an e-commerce on social media has reliability on the quality of system, quality of information and quality of service, it will greatly affect the number of visits to e-commerce which will certainly be a hedge against the quantity of purchases on e-commerce". Trust, therefore is an important attribute of hedging. Although there are plethora of studies on trust and e-government, few have explored hedging in the context of e-government and specifically from an employee or citizen perspective.

\section{METHODOLOGY}

To explore hedging strategies used by online users to guard against risks associated with the use of e-Gov services, this study followed an interpretive approach. The study was inductive in nature given that "hedging" as a concept has not been well researched and theorised in the information systems discipline. Using interviews as a means of data collection, the researchers sought to engage participants with e-Gov, specifically their experiences in engaging with online services offered by government and strategies they use if any, of mitigating risks associated with consuming online services. Data was collected from government employees in the Western Cape of South Africa. The motivation to focus on government employees was firstly because, whilst there have been several studies on citizen adoption, few have examined public sector adoption and use of eGov services. This is a limitation given the employee's organizational contextual constraints towards their adoption and usage. Also, focusing on the employee could also provide insights into how best to develop systems that are address both citizen and public employee concerns. This can be achieved through, for example co-design of the systems in the initial phase of the innovation (Ruiz Ben et al 2017).

The Western Cape province of South Africa is one of the provinces which boasts as the tech hub of Africa, with Cape Town as the New Silicon Valley (https://www.siliconcape.com/). The province is the second-highest contributor to South Africa's GDP and therefore serves as a good context. In total, sixteen interviews were conducted and thematic analysis was employed to study the interviews to identify patterns associated to the phenomenon of interest. Firstly, the data was transcribed the transcribed interviews became the data corpus through which the main data analysis was performed from. Then, initial reading and rereading of each transcribed document was done with the purpose of identifying key words that spoke towards the research problem and goal of the study. These key words became the first step towards the development of initial codes for the analysis. The codes were then compared and instances where the codes appeared to point to the same meaning, these codes were grouped together to form a theme. For example, initial codes identified as "physically seeking assistance", "call in to seek help", and "log a call online" were grouped together to form one major theme titled Use of multichannels for e-Gov services. This process was iterative in nature, as it required going back to the themes and codes to ensure the aggregation of the theme does reflect what the codes intend, and that the codes correspond to the data extract. Three main themes were identified: use of multichannels to access e-Gov services, friends with benefits and "blessers"; and Limited use of eGov services. These themes are discussed below. 


\section{FINDINGS AND DISCUSSION}

\subsection{Demographic Findings}

Sixteen respondents participated in the study as shown in Table 1. All respondents, with the exception of Resp 16

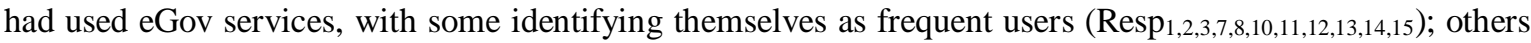
as infrequent users $\left(\operatorname{Resp}_{4,5,6,9}\right)$. It is interesting to note that the majority of the younger respondents identified as frequent users of eGov services. Our findings are in line with Gupta et al (2017) who posits that "old aged employees are generally not comfortable with computers and ICT, and hence reluctant towards adopting e-government, as com-pared to young ones". Nine of the respondents had a national certificate or a diploma as their highest education qualification. Six respondents identified as female and the remaining identified as male.

Table 1. Respondent demographic Profile

\begin{tabular}{lllll}
\hline Respondent & Gender & Age & Education & Government \\
\hline Resp1 & Male & 31 & National Certificate/Diploma & Municipality \\
Resp2 & Male & 33 & National Certificate/Diploma & Municipality \\
Resp $_{3}$ & Male & 20 & National Certificate/Diploma & Municipality \\
Resp$_{4}$ & Female & 26 & National Certificate/Diploma & Municipality \\
Resp5 & Male & 40 & National Certificate/Diploma & Municipality \\
Resp6 & Male & 42 & National Certificate/Diploma & Municipality \\
Resp7 & Male & 42 & Master's Degree & Municipality \\
Resp8 & Male & 44 & National Certificate/Diploma & Municipality \\
Resp9 & Female & 52 & Higher Diploma & Department of Home Affair \\
Resp 10 & Male & 38 & Postgraduate certificate & Department of Home Affair \\
Resp 11 & Male & 27 & Bachelor's degree & South Africa Revenue service \\
Resp 12 & Male & 27 & Postgraduate certificate & South Africa Revenue service \\
Resp 13 & Female & 45 & National Certificate/Diploma & Department of Justice \\
Resp14 & Female & 39 & National Certificate/Diploma & Supply chain management \\
Resp15 & Female & 28 & Honors Degree & Department of labor \\
Resp 16 & Female & 60 & Higher Diploma & Social Security Agency \\
\hline
\end{tabular}

\subsection{Hedging Strategies}

\subsubsection{Use of Multichannels for e-Gov Services}

Most respondents in this study were educated - possessing a national certificate or diploma as minimal qualification. They however, identified literacy as a factor of consideration when using e-Gov because the content presented online is difficult to understand. To avoid the risk of continuing with the online task, due to lack of understanding what is required, they reverted to traditional channels of communicating with government as Resp 8 explains:

reading and comprehending technology language is different from reading and comprehending non IT language. When it comes to following instructions on how to use online services, it is difficult to understand and I would prefer to have someone physically guiding me. When online filling a form, iam usually confused (chuckles), so I go to their offices personally, and sometimes I phone them. This is easier for me.

The use of technological jargon increases confusion and has the potential to develop computer anxiety amongst users (Oluwalola 2015). Although this jargon emanates from the developers who come from different disciplines, it is imperative that it is contained during development as it can lead to misunderstandings (Blanson Henkemans, 2015), and the ramification observed during adoption. Respondent ${ }_{15}$ agrees and indicates that this problem is bigger for those whose English is not their first language or are older... they not going to know what to do. Several authors have called for the need to understand how technological media influence contexts and forms of expression and communication because "language technologies vary dramatically and being 
literate in one mode does not imply being literate in all modes" (Chun 2016).

Although there were some citizens who were aware of the services (awareness) and able to understand the technical jargon presented to them (literacy), there was a perception that there was a need from service providers to explain in detail how to start using a particular service and the various activities involved in the consumption of the service. For example, most respondents identified the tax process as being tedious and complicated. One of the respondents (Resp 12$)$ explains:

there are a lots of tax payers who need to be educated on how it works, they feel like they being robbed. You must be aware of the processes. Where does it start, what signatures do I need when I reach which phase of the process, what it consists of, how do I know I have reached the end? People do not know so they visit the offices physically - simply because they failed to understand the tax process.

The use of multichannel was also employed to confirm the details presented online because according to $\operatorname{Resp}_{2}$ you cannot trust everything online. Some individual can pose as the municipality of Cape Town when they are sitting in some island ready to trick you. I call the numbers they have given me to verify and also go in myself to actually see that it is indeed them. The findings therefore show that citizens would use multichannel approach (such as revert to traditional channels of access when they fail to understand how to consume an online services or require to confirm the actual existence of the eGov service), as a hedging strategy to respond to the uncertainties presented when consuming an eGov service.

\subsubsection{Friends with Benefits and "Blessers"}

A consistent claim from respondents was the fear of not completing the online task correctly due to poor digital competencies, and in so doing jeopardize my money - imagine I had already paid and everything (gasps)! (Resp ${ }_{3}$ ). Understanding the technical language used online was one challenge, and the other was having the skill set and competency required to engage with the technology itself. Whilst most respondents indicated that they have access to ICTs, they noted that they do not have the specialized skills to complete an online service without assistance as Resp 4 explains:

I mostly ask my friend to help me out. Most of us do these transactions when we are at work because it cheaper that way, and when we stuck we ask friends who have these sophisticated skills. Of course you have to trust the friend, and having a friend with benefits helps.

Several respondents called for the government to invest in all employees instead of investing only in administrators and managers because some employees do not have the skills and are now forced to find alternatives means that are not safe ( $\left.\operatorname{Resp}_{6}\right)$. According to McLeod and Savoy (2015) major benefits can be derived from an introductory level computer courses designed and structured in a way to provide the basic steps to becoming technologically literate. Neves et al (2018) identified digital literacy - a user's ability to have prior and current digital skills to navigate online - as an instrumental factor that can facilitate but also hinder adoption of eGov services. Whilst friends with benefits were used to assist in navigating the online platform, they were also used when access to eGov services was not possible due to lack of data. Access to the device such as a computer or a mobile phone that allows usage of online services was not a problem; but access to data, which was usually associated with high costs was problematic as Resp 5 explains:

Data wise I don't have a problem, no access problems. I can afford. But what about others who can't? Most people cannot afford and they turn to friends who loads them with credit-sometimes, if not most time, at a cost in kind. Government must put procedures in place as this can lead to blessers here because we have young employees coming in.

A "blesser is defined as "an older rich man who tend to entice young women with money and expensive gifts in exchange for sexual favours" (Mampane 2018). When users become weary of risking to lose their finances or incur costs when completing a task online, they indulge in friends with benefits or blesser hedging strategies. That is, having friends with benefits or blessers is perceived by some respondents as a potential means of cushioning oneself of any risk posed by the use of online services. This is not new in the South African context as Masenya $(2017,121)$ explains that "while many a young person, (cf. especially girl children in the context of the South African sugar daddies/male 'blessers' and sugar mummies/female blessers) get entangled in such relationships due to poverty (in some cases even being supported by parents), many of them are motivated by the materialistic context of globalization". This is further compounded by the "Fear of Missing 
Out and the ubiquitous nature of 'being on', in case we miss something”' (Andrews, 2018). To address some of these challenges, so as to appear connected and relevant "the emergence of blessers seems to be an escaping route" (Thobejane et al 2017).

\subsubsection{Limited Use of eGov Services}

Most respondents identified the ease of using online service and the convenience it provides. Resp $\mathrm{p}_{12}$ comprehensively explains:

If it is during tax season, the process of completing the tax invoice traditionally can take long, you have to take leave from work sometimes and you go to the main office. But it does not take long online and you don't have to take leave from work. Most of my accounts are on line. I download the apps so when I get paid I just transfer the money, I don't have to go to the office. , download apps, don't have to queue just transfer.

Yet, despite these conveniences, most opt to use eGov services less frequently. Two reasons were presented. Firstly, that "no one can confidently confirm, everything that is online is true and works...like there is no campaign about it like other government initiative have $\left(\operatorname{Resp}_{2}\right)$. Whilst they perceived the conveniences and benefits associated with eGov services, they adopted a limited-use hedging strategy to mitigate risk. The lack of awareness of eGov services and respondents lack of observing many people who have used eGov services was the main factor influencing the adoption of limited-use hedging strategy. For example, Resp 9 notes that most people are not aware of these services, including myself. I was not aware you could apply for a passport online. I became aware of it after working here [in government]. Resp 7 echoes similar sentiments, I was not initially aware that I can use the on line service. I become aware of it only last year almost by accident-from a work mate in another department. According to Resp 15 , lack of awareness is driven by government's lack of strategic digital marketing tools because online services are not advertised, not on social media, billboards, or on other tv channels. Instead it's normally done on traditional SABC channels - who watches them? The perception was that government's marketing initiative should employee new digital tools and techniques to be able to reach all citizens. These findings echo those in literature, highlighting that to provide better public services through the adoption and use of eGov, marketing remains an obstacle (Otniel, 2015). Teerling and Pieterson (2010) advocate for the application of different marketing strategies to lead citizens to electronic channels and thus increase the usage of eGov services.

The second reason was the quality associated with eGov services. System quality in this study was perceived as availability (online) and responsiveness of the system. Most respondents argued that online systems do not work and it is frustrating ( $\left.\operatorname{Resp}_{13}\right)$ when for example you uploading documents. It does not upload properly and you spending a lot of time on line, and this translates into unnecessary costs which were supposed to be an advantage of online in the first place ( $\left.\operatorname{Resp}_{15}\right)$. Previous studies have also called for eGov services "to be available as much as possible, preferably 24/7, without technical or organizational issues, ensuring the citizen a constant and problem-free access to the portal, regardless of time or geographic location" (Sá et al, 2017). According to Resp 8 the problem here is that the online system sometimes is not working properly, they are offline and therefore not dependable. You can't trust it. These findings of service availability and responsiveness, have been reported in earlier studies and are amongst other technical performance features, important criterion for determining the quality of eGov services (Jansen and Ølnes, 2016). To avert the risks imposed by system quality (service availability and responsiveness in this case), respondents engaged in limited-use hedging strategies of eGov services.

\section{CONCLUSION}

The purpose of this study was to explore hedging strategies online users employ to guard against risks associated with the use of e-Gov services in South Africa. The study identified three key hedging strategies. The multichannel hedging strategy was used in instances when users faced technological language or jargon that increased confusion and has the potential to develop computer anxiety amongst users; when confirmation of information and also when the consumption of an e-Gov services was perceived to be difficult. The friends-with benefit/blesser hedging strategy was employed when users perceived the cost associated with e-Gov services was high; and when they perceived themselves to have limited digital competencies to engage 
with e-Gov services. In this instance, the risk, if incurred at all, would befall the friends-with benefit/blesser. The limited-use hedging strategy was adopted and influenced by the perception of low quality delivery of e-Gove services, lack of awareness of availability of e-Gove services due to, among others, no digital marketing of these services. These findings, provide an alternative explanation as to how online users in the South African context manage the risk and uncertainty present online. Using these results, developers are able to develop eGov services that meet user's needs amidst their contextual challenges they face. The study has some limitation, mainly from the sample used. By understanding the phenomenon of hedging from government employee's perspective alone, and only from one province in South Africa, does not provide a holistic view, and therefore cannot be generalized to other population groups in South Africa. Future work can expand on this study and understand the phenomenon from a wider audience of e-Gov users.

\section{REFERENCES}

Al-Hujran, O., Al-Debei, M. M., Chatfield, A., \& Migdadi, M. (2015). The imperative of influencing citizen attitude toward e-government adoption and use. Computers in human Behavior, 53, 189-203

Alzahrani, L., Al-Karaghouli, W., \& Weerakkody, V. (2018). Investigating the impact of citizens' trust toward the successful adoption of e-government: A multigroup analysis of gender, age, and internet experience. Information Systems Management, 35(2), 124-146.

Andrews L (2018). \#YouthReport2018: Being a teenager in 2018, more pressure than peer pressure. Retrieved from https://www.bizcommunity.com/Article/196/347/181580.html

Bélanger, F., \& Carter, L. (2008). Trust and risk in e-government adoption. The Journal of Strategic Information Systems, $17(2), 165-176$

Ruiz Ben, E., Scholl, M., \& Ehrlich, P. (2017). Exploring the Adoption of E-Government Tools with WISE Work Index.

Bhattacharya, D., Gulla, U., \& Gupta, M. P. (2012). E-service quality model for Indian government portals: citizens' perspective. Journal of Enterprise Information Management, 25(3), 246-271

Blanson Henkemans, O. A., van Empelen, P., Paradies, G. L., Looije, R., \& Neerincx, M. A. (2015) Lost in persuasion: a multidisciplinary approach for developing usable, effective, and reproducible persuasive technology for health promotion. In Proceedings of the 9th International Conference on Pervasive Computing Technologies for Healthcare, 49-56

Chen, J. V., Jubilado, R. J. M., Capistrano, E. P. S., \& Yen, D. C. (2015). Factors affecting online tax filing-An application of the IS Success Model and trust theory. Computers in Human Behavior, 43, 251-262

Chun, D., Kern, R., \& Smith, B. (2016). Technology in language use, language teaching, and language learning. The Modern Language Journal, 100(S1), 64-80

D'cruz, J. (2015). Trust, Trustworthiness, and the Moral Consequence of Consistency. Journal of the American Philosophical Association, 1(3), 467-484

Distel, B. (2018). Bringing Light into the Shadows: A Qualitative Interview Study on Citizens' Non-Adoption of e-Government. Electronic Journal of e-Government, 16(2), 98-105

Dorfman, J. H., \& Karali, B. (2010). Do farmers hedge optimally or by habit? A Bayesian partial-adjustment model of farmer hedging. Journal of Agricultural and Applied Economics, 42(4), 791-803

E-government Survey. https://publicadministration.un.org/egovkb/Portals/egovkb/Documents/un/201 8-Survey/ E-Government\%20Survey\%202018_FINAL\%20for\%20web.pdf Retrieved March 2019

Gupta, K. P., Bhaskar, P., \& Singh, S. (2017). Prioritization of factors influencing employee adoption of e-government using the analytic hierarchy process. Journal of Systems and Information Technology, 19(1/2), 116-137

Hariguna, T., \& Berlilana, B. (2017). Understanding of Antecedents to Achieve Customer Trust and Customer Intention to Purchase E-Commerce in Social Media, an Empirical Assessment. International Journal of Electrical and Computer Engineering, 7(3), 1240

Jackson, V. (2014). Power, trust, and network complexity: three logics of hedging in Asian security. International Relations of the Asia-Pacific, 14(3), 331-356

Jansen, A., \& Ølnes, S. (2016). The nature of public e-services and their quality dimensions. Government Information Quarterly, 33(4), 647-657

Joseph, B. K., \& Du Plessis, T. (2015). Consumers' Awareness of the Value of e-Government in Zambia: Empirical Evidence. International Journal of Electronic Government Research (IJEGR), 11(3), 1-23

Koga, K. (2017). The concept of "hedging" revisited: the case of Japan's foreign policy strategy in East Asia's power shift. International Studies Review, 20(4), 633-660 
Lallmahomed, M. Z., Lallmahomed, N., \& Lallmahomed, G. M. (2017). Factors influencing the adoption of e-Government services in Mauritius. Telematics and Informatics, 34(4), 57-72

Liu, D., \& Carter, L. (2018) Impact of citizens' privacy concerns on e-government adoption. In Proceedings of the 19th Annual International Conference on Digital Government Research: Governance in the Data Age (p. 27).

Mampane, J. N. (2018). Exploring the "Blesser and Blessee" Phenomenon: Young Women, Transactional Sex, and HIV in Rural South Africa. SAGE Open, 8(4), 1-9, 2158244018806343

Masenya, M. (2017). Reading Proverbs 7 in the context of female'blessers' and sugar mamas in South Africa. Scriptura, $116,120-132$.

McLeod, A., \& Savoy, A. (2015). The Building Blocks for Enhanced Technological Literacy. CTE Journal, 3(2), 2-14.

Mellouli, M., Bentahar, O., \& Bidan, M. (2016). Trust and e-government acceptance: The case of Tunisian on-line tax filing. The Electronic Journal Information Systems Evaluation, 19(3), 197-212.

Munyoka, W., \& Maharaj, M. S. (2019). Privacy, security, trust, risk and optimism bias in e-government use: The case of two Southern African Development Community countries. South African Journal of Information Management, 21(1), $1-9$

Mutula, S. M., \& Mostert, J. (2010). Challenges and opportunities of e-government in South Africa. The electronic library, 28(1), 38-53

Oluwalola, F. K. (2015). Effect of emotion on distance e-learning - The fear of technology. International Journal of Social Science and Humanity, 5(11), 966-970

Otniel, D. (2015). The challenges of e-government 2.0 projects in Romania: An insight. Annals-Economy Series, 4, 24-29

Picazo-Vela, S., Gutiérrez-Martínez, I., \& Luna-Reyes, L. F. (2012). Understanding risks, benefits, and strategic alternatives of social media applications in the public sector. Government information quarterly, 29(4), 504-511

Rao, L., Liu, X., Xie, L., \& Pang, Z. (2011). Hedging against uncertainty: A tale of internet data center operations under smart grid environment. IEEE Transactions on Smart Grid, 2(3), 555-563

Rashid, M. A. A., \& Othman, M. N. A. (2010). User adoption and use of e-government online service. Gading Journal for the Social Sciences, 14(01)

Reich, T., \& Wheeler, S. C. (2016). The good and bad of ambivalence: Desiring ambivalence under outcome uncertainty. Journal of Personality and Social Psychology, 110(4), 493

Sá, F., Rocha, Á., Gonçalves, J., \& Cota, M. P. (2017). Model for the quality of local government online services. Telematics and Informatics, 34(5), 413-421

Salman, M. (2017). Strategic Hedging and Unipolarity's Demise: The Case of China's Strategic Hedging. Asian Politics \& Policy, 9(3), 354-377

Shareef, M. A., Kumar, V., Kumar, U., \& Dwivedi, Y. K. (2011). e-Government Adoption Model (GAM): Differing service maturity levels. Government information quarterly, 28(1), 17-35

Taušer, J., \& Čajka, R. (2016). Hedging techniques in commodity risk management. Agricultural Economics, 60(4), 174-182

Teerling, M. L., \& Pieterson, W. (2010). Multichannel marketing: An experiment on guiding citizens to the electronic channels. Government Information Quarterly, 27(1), 98-107

Thobejane, T. D., Mulaudzi, T. P., \& Zitha, R. (2017). Factors leading to "blesser-blessee" relationships amongst female students: The case of a rural university in Thulamela Municipality, Limpopo Province, South Africa. Gender and Behaviour, 15(2), 8716-8731.

UN E - Goverment Survey. https://publicadministration.un.org/egovkb/en-us/reports/un-e-governmentsurvey-2016.

van Esterik-Plasmeijer, P. W., \& van Raaij, W. F. (2017). Banking system trust, bank trust, and bank loyalty. International Journal of Bank Marketing, 35(1), 97-111

Venkatesh, V., Thong, J. Y., Chan, F. K., \& Hu, P. J. (2016). Managing citizens' uncertainty in e-government services: The mediating and moderating roles of transparency and trust. Information Systems Research, 27(1), 87-111 